\title{
A gasometric method to determine erythrocyte catalase activity
}

\section{A.J.S. Siqueira ${ }^{1}$, \\ J.O. Remião ${ }^{1}$ C.R.J. Azambuja ${ }^{2}$}

A.M.P. Azevedo ${ }^{1}$ and

\author{
'Departamento de Ciências Fisiológicas, Fundação Faculdade Federal de Ciências \\ Médicas de Porto Alegre, Porto Alegre, RS, Brasil \\ 2Instituto de Matemática, Pontifícia Universidade Católica do Rio Grande do Sul, \\ Porto Alegre, RS, Brasil
}

\section{Correspondence \\ A.M.P. Azevedo \\ Disciplina de Bioquímica \\ Fundação Faculdade Federal de \\ Ciências Médicas de Porto Alegre \\ Rua Sarmento Leite, 245 \\ 90050-170 Porto Alegre, RS \\ Brasil \\ Fax: + 55-51-226-7913 \\ E-mail: anzevedo@ fffcmpa.tche.br \\ Research supported by the \\ Fundação Faculdade Federal de \\ Ciências M édicas de Porto Alegre.}

Received July 22, 1998

Accepted June 9, 1999

\section{Abstract}

We describe a new gasometric method to determine erythrocyte catalase activity by the measurement of the volume of oxygen produced as a result of hydrogen peroxide decomposition in a system where enzyme and substrate are separated in a special reaction test tube connected to a manometer and the reagents are mixed with a

Key words

- Erythrocyte

- Catalase assay

- Gasometry motor-driven stirrer. The position of the reagents in the test tube permits the continuous measurement of oxygen evolution from the time of mixing, without the need to stop the reaction by the addition of acid after each incubation time. The enzyme activity is reported as $K_{H b}$, i.e., mg hydrogen peroxide decomposed per second per gram of hemoglobin $\left(\mathrm{s}^{-1} \mathrm{~g} \mathrm{Hb}^{-1}\right)$. The value obtained for catalase activity in 28 samples of hemolyzed human blood was $94.4 \pm 6.17 \mathrm{mg} \mathrm{H}_{2} \mathrm{O}_{2} \mathrm{~s}^{-1}$ $\mathrm{g} \mathrm{Hb}^{-1}$. The results obtained were precise and consistent, indicating that this rapid, simple and inexpensive method could be useful for research and routine work.

\section{Introduction}

Several methods have been described for the measurement of erythrocyte catalase activity. Most are based on the measurement of residual hydrogen peroxide after incubation with the enzyme or the volume of oxygen produced by decomposition of the substrate. Traditional gasometric methods include manometers equipped with a burette (1), the ureometer of Ambard (2), specially designed manometers (3), as well as the Van Slyke apparatus (4). According to Rorth and Jensen (5) none of these methods can be considered fully satisfactory due to the extremely rapid action of catalase on hydrogen peroxide, which renders the reaction difficult to follow at the beginning (6). In addition, there is a rapid decrease in the reaction velocity just a few seconds after the beginning of the reaction due to the formation of an inactive enzyme-substrate complex (ES III), especially when the concentration of the substrate is above $0.1 \mathrm{M}$ (7-10). Other nongasometric methods have been described: these include iodometry $(11,12)$, titrimetry using potassium permanganate $(13,14)$, polarimetry $(15)$, spectrophotometry (16-18), colorimetry $(19,20)$ and methods based on luminol chemiluminescence $(21,22)$.

Catalase activity must be measured when substrate decomposition follows a first order kinetics, i.e., before the formation of inactive intermediate complexes (9). The initial ve- 
locity is considered to be constant only during the first few seconds after the beginning of the reaction (8), so that product formation must be measured immediately after mixing of the reagents for precise results (5). In addition, for catalase measurement attention must be paid to important technical details to obtain precise results. Blood samples are initially hemolyzed with distilled water, since enzyme activity is higher in the hemolysate. Blood samples can be stored at $4^{\circ} \mathrm{C}$ for more than $72 \mathrm{~h}$ and some samples will not lose activity for as long as 21 days. In contrast, after dilution in water enzyme activity is reduced presumably because the enzyme is rapidly denatured $(23,24)$.

Catalase activity can be measured at room temperature due to the low activation energy required for decomposition of the substrate (10). Tudhope (24) measured enzyme activity at temperatures of $1,8,14$ and $22^{\circ} \mathrm{C}$ and did not observe significant differences, whereas at $37^{\circ} \mathrm{C}$ there was some enzyme denaturation. According to Bonnichsen et al. (25), when determining catalase activity, the substrate concentrations should be low, the enzyme concentrations high and the incubation time short.

Maral et al. (21) determined erythrocyte catalase activity in different species by measuring the light emitted from oxidation of luminol by horseradish peroxidase. They considered normal values for human blood to be 100 and reported other animal species as percent of this reference value.

In the present study we describe a gasometric method suited for measurement of oxygen evolution from the decomposition of hydrogen peroxide by catalase, starting from the time when the reagents are first mixed, without the need for acid denaturation of the enzyme for each measurement.

\section{Material and Methods}

Blood samples were obtained from healthy human adult subjects of both sexes aged 18 to 60 years and collected into heparinized flasks. Hemoglobin $(\mathrm{Hb})$ levels were determined with an automatic analyzer (Reflotron, Boehringer-Mannheim, Mannhein, Germany). Catalase activity was determined in duplicate at room temperature (range 20 to $24^{\circ} \mathrm{C}$ ), measuring the volume of oxygen produced by decomposition of hydrogen peroxide. We also determined catalase activity in 10 samples each of different species (chicken, sheep, rabbit and horse) and the results were compared to those of Maral et al. (21).

\section{Measurement of oxygen}

Hydrogen peroxide decomposition occurred in a reaction tube (RT) similar to that described by Meldrum and Roughton (26) which was connected to a manometer (MA) opened to the atmosphere. The reagents were mixed by connecting the reaction tube to a stirring motor $(\mathrm{M})$. The motor, adapted from an electric knife, moves the blade monoaxially at a frequency of 1,950 cycles per minute and an amplitude of $0.7 \mathrm{~cm}$. A support (ST) for the RT was welded on the blade (B) as shown in Figure 1.

\section{Calibration of the manometer}

The manometer was calibrated in order to determine the amount of hydrogen peroxide that displaces the manometer column by a distance of $1.0 \mathrm{~cm}$ after complete decomposition. This is the manometer factor $(\mathrm{Fm})$. The manometer was filled with a solution of $0.15 \mathrm{~g} \%$ Congo red. The calibration was achieved by dispensing $0.5 \mathrm{ml}$ of $0.060 \mathrm{~N}$ hydrogen peroxide $\left(0.51 \mathrm{mg} \mathrm{H}_{2} \mathrm{O}_{2}\right)$ and 0.5 $\mathrm{ml}$ of $1 \%$ sulfuric acid $(\mathrm{v} / \mathrm{v})$ into one of the arms of the RT and $1.0 \mathrm{ml}$ of $0.25 \mathrm{~N}$ potassium permanganate into the other. The RT was capped and the internal pressure of the system was then equilibrated with the atmospheric pressure through a valve $(\mathrm{V})$ (see Figure 1). The initial position of the manometric liquid column (baseline) was recorded 
and the stirrer was then turned on. The stirrer was turned off after the displacement of the manometer liquid column had stopped, which indicated the decomposition of $0.51 \mathrm{mg}$ of hydrogen peroxide. The displacement distance $(h)$ in centimeters was recorded and further corrected for the standard conditions of temperature and pressure to obtain the corrected distance $\left(h_{c}\right)$. The $\frac{0.51}{h_{c}}$ ratio is a constant that is characteristic for each manometer used in this technique.

\section{Determination of catalase activity}

The procedure was the same as described for calibration except that we dispensed $1 \mathrm{ml}$ of $0.03 \mathrm{~N}$ hydrogen peroxide in $0.1 \mathrm{M}$ sodium phosphate buffer, $\mathrm{pH} 7.0$, into one arm of the RT and $1 \mathrm{ml}$ of hemolyzed blood solution in distilled water (containing $0.4 \mathrm{mg}$ of $\mathrm{Hb}$ ) into the other. $h$ was recorded at the times $(t)$ of 15,23 and $30 \mathrm{~s}$, and later corrected for standard conditions of temperature and pressure.

Since catalase kinetics follows a parabolic equation (4), the initial velocity $k$ can be determined by the following equation:

$$
h_{c} \cdot F m=k \sqrt{t}
$$

or, in another form,

$$
k=\frac{h_{c}}{\sqrt{t}} \cdot F m,
$$

where $h_{c} \cdot F m$ equals mg of hydrogen peroxide decomposed during time $t$.

By performing three determinations at 15,23 and $30 \mathrm{~s}, k$ can be calculated as follows:

$$
k=\frac{\sum h_{c^{*}} F m}{\sum \sqrt{t}}
$$

This is possible because $k$ is constant and the coordinate points:

$$
\sqrt{15}, h_{c 1} \cdot F m ; \sqrt{23}, h_{c 2} \cdot F m \text { and } \sqrt{30}, h_{c 3} \cdot F m
$$

are part of the same straight line. Then,

$$
k=\frac{\sum h_{c}}{\sqrt{15}+\sqrt{23}+\sqrt{30}}=\frac{\sum h_{c}}{14.14} \text { or } k=0.707 \cdot \sum h_{c} \cdot F m,
$$

where $k$ represents the amount $(\mathrm{mg})$ of hy- drogen peroxide decomposed in one second per $0.4 \mathrm{mg}$ of $\mathrm{Hb}$. Catalase activity was reported as the amount $(\mathrm{mg})$ of hydrogen peroxide decomposed in one second per gram of hemoglobin $\left(K_{H b}\right)$. Since $0.4 \mathrm{mg}$ of $\mathrm{Hb}$ was dispensed into RT, $K_{H b}=2,500 k$, or $K_{H b}=2,500 \cdot 0.707 \cdot \sum h_{c} \cdot F m$, or $K_{H b}=176.8$. $\sum h_{c} \cdot F m$.

\section{Parabolic behavior of the reactio}

The parameter was measured by hydrogen peroxide decomposition at the times of $10,15,20,25,30,35$ and $40 \mathrm{~s}$. The theoretical curve obtained was drawn after determining the value of $k$ by the calculations shown above.

\section{Relationship between catalase activity and hemoglobin}

Catalase activity was measured in four different dilutions of blood, namely 0.08 , $0.12,0.16$ and $0.20 \mathrm{mgHb} / \mathrm{ml}$, and the correlation of enzyme activity with $\mathrm{Hb}$ concentration was established.

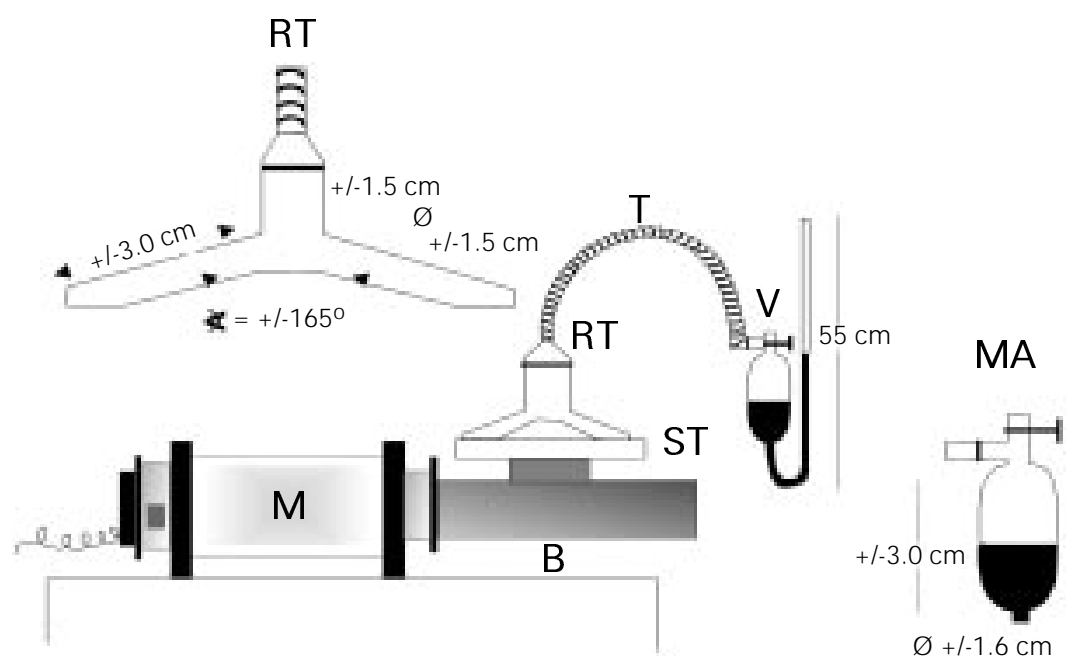

Figure 1 - Device for the measurement of oxygen evolution. The reaction test tube (RT) is held by a support (ST), connected to the stirrer motor (M) through a steel bar (B). RT is connected to the manometer (MA) by a rubber tubing $(\mathrm{T})$. The bulb of the manometer is provided with a valve $(\mathrm{V})$ to equilibrate the system with the atmospheric pressure before mixing the reagents. RT total capacity is $12.0 \mathrm{ml}$. 
Figure 2 - Experimental curve showing the amount (mg) of hydrogen peroxide decomposed by catalase as a function of time in seconds. Hemoglobin concentration was $0.4 \mathrm{mg}$ in $1.0 \mathrm{ml}$. The solid line indicates theoretical values for a parabola.
Figure 3 - Correlation between the amount $(\mathrm{mg})$ of hydrogen peroxide decomposed by catalase and the square root of time, in seconds. The straight line obhavior of the data in Figure 2. The equation of the straight line is $y=0.0399 x-0.0029 . R^{2}=$ 0.9838 .

Figure 4 - Correlation between the amount $(\mathrm{mg})$ of hydrogen peroxide decomposed by catalase as a function of $\mathrm{mg}$ hemoglobin. The equation of the straight line is $y=0.1726 x+$ $0.0019 . R^{2}=0.9818$ tained indicates the parabolic be-
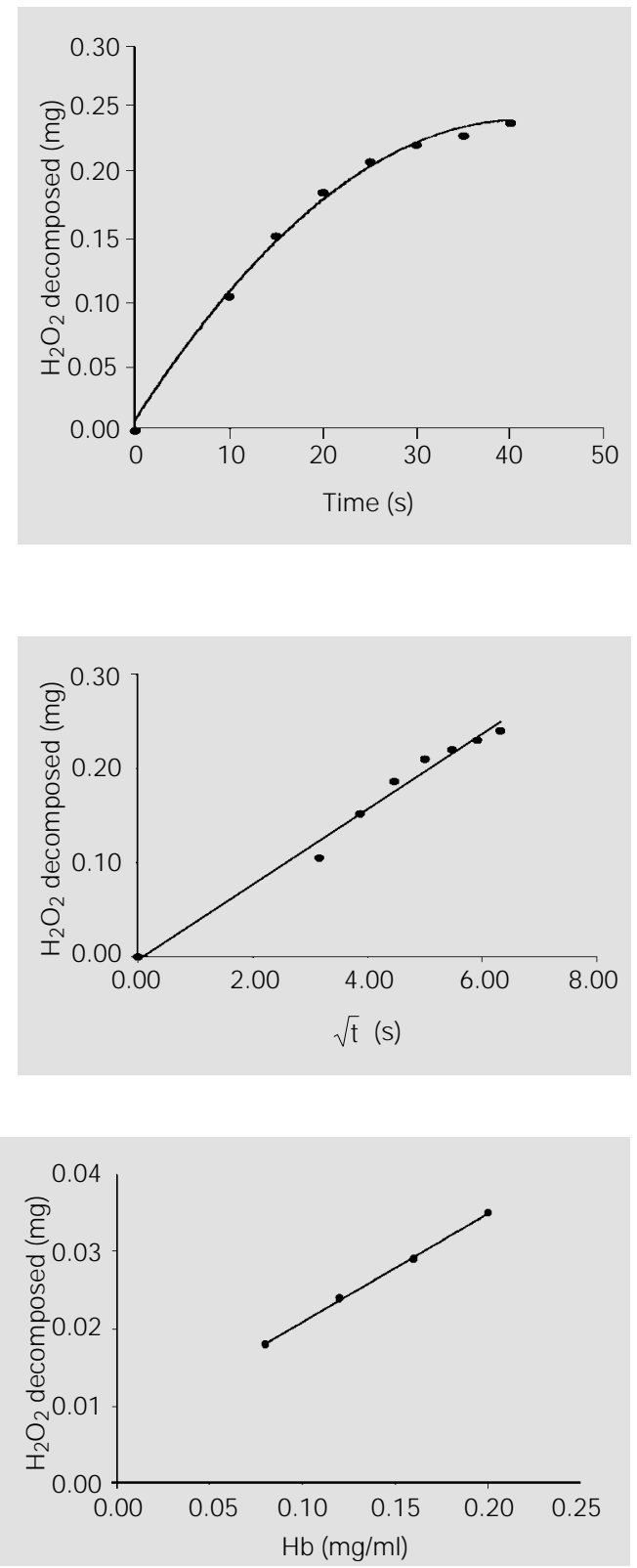

Figure 5 - Decrease in catalase activity as a function of time. Blood was diluted in distilled water at room temperature (range 20 to $24^{\circ} \mathrm{C}$ ). The equation of the straight line is $y=-0.01 x+$ $0.31 . R^{2}=1.0$. The inactivation rate was $5 \% / \mathrm{h}$.

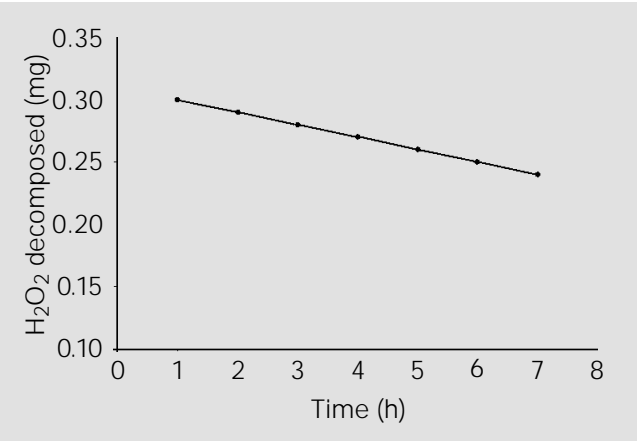

\section{Enzyme denaturation in hemolyzed blood}

Two blood samples were analyzed at l-h intervals for $7 \mathrm{~h}$ to determine the loss of enzymatic activity by denaturation in distilled water at room temperature (range 20 to $\left.24^{\circ} \mathrm{C}\right)$. The hemoglobin concentration used $(0.4 \mathrm{mg} / \mathrm{dl})$ was the same as indicated in the description of the technique.

\section{Equivalence of units}

We established the equivalence between the relative activity scale reported by Maral et al. (21) and our data, taking the human value as $100 \%$ in both series.

\section{Results and Discussion}

The relationship between the amount of hydrogen peroxide decomposed and the time in seconds, obtained experimentally, is shown in Figure 2. The same figure also shows a theoretical curve calculated from the experimental data using the equation for a parabola. Figure 3 shows that the experimental data for the amount ( $\mathrm{mg}$ ) of hydrogen peroxide decomposed are related to the square root of the corresponding time in seconds $(\sqrt{t})$.The correlation between the enzymatic decomposition of hydrogen peroxide and the amount (mg) of hemoglobin present in the system is shown in Figure 4. The loss of enzyme activity as a function of time at room temperature was calculated to be $5 \% / \mathrm{h}$ (Figure 5). Figure 6 shows the equivalence between our data for different species and those of Maral et al. (21). The repetitions executed in all samples throughout the experiment showed a negligible deviation $(2.0 \pm 1.5 \%)$.

The value obtained for catalase activity $\left(K_{H b}\right)$ for 28 samples of hemolyzed human blood was $94.4 \pm 6.17 \mathrm{mg} \mathrm{H}_{2} \mathrm{O}_{2} \mathrm{~s}^{-1} \mathrm{~g} \mathrm{Hb}^{-1}$.

In this study we did not consider the sex of blood donors because this parameter does not apparently influence catalase activity (8,24,27-30). However, two conflicting re- 
ports by Goth (17) and by Bolzan et al. (31) have described higher catalase activity for males and females, respectively.

The two time curves obtained (Figure 2), one with the experimental data and the other calculated by equation,

$$
k=\frac{h_{c}}{\sqrt{t}},
$$

have a distribution of the parabolic type and are almost coincident during the time interval between 15 and $35 \mathrm{~s}$. This parabolic curve is confirmed in Figure 3, where a straight line was obtained when the amount of hydrogen peroxide decomposed was plotted as a function of the square root of time, which is a characteristic of the reaction catalyzed by catalase (4).

The results obtained with the four blood dilutions (Figure 4) show that there is a relationship between catalase activity and hemoglobin concentrations which agrees with Kirk (4), Takahara et al. (7) and Miller (23).

Our data indicate that normal catalase levels (the average \pm two standard deviations) is between 82.06 and 106.74 , which is

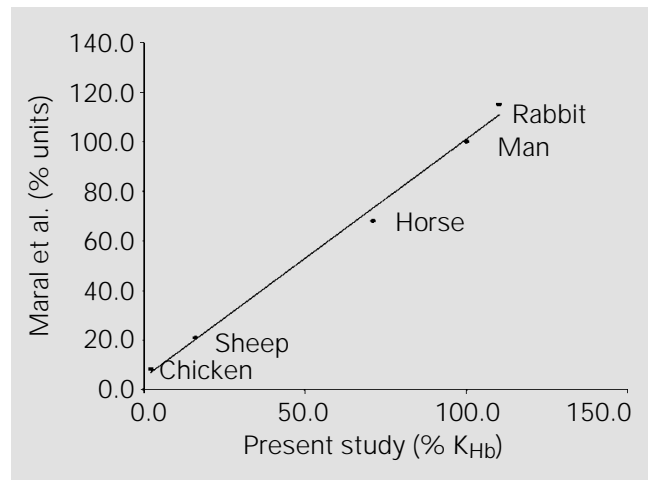

Figure 6 - Relative enythrocyte catalase activity for different species. The figure shows the similarity between the data of Maral et al. (21) and those of the present study. In each series the value for human erythrocytes was taken as $100 \%$. The equation of the straight line is $y=$ $0.9622 x+4.9034 . R^{2}=0.9945$. much better than the average \pm three standard deviations suggested by others $(28,29)$.

\section{Acknowledgments}

We thank Mirna Barison from the Blood Bank of ISCMPA for scientific assistance and Alessandro D'Ávila da Silva, Mila Pontremoli and Teresinha Stein for technical support. We also thank Prof. Eliete B. Hauser for meaningful mathematical discussions.

\section{References}

1. Morgulis S (1921). A study of the catalase reaction. J ournal of Biological Chemistry, 47: 341-375.

2. Maisin J \& Pourbaix Y (1938). Influence des injections de peroxyde de diformaldéhyde sur l'activité de la catalase du sang. Comptes Rendus de la Société Belge de Biologie, 129: 46-49.

3. Greenfield RE \& Price VE (1954). Liver catalase I - a manometric determination of catalase activity. J ournal of Biological Chemistry, 209: 355-361.

4. Kirk J E (1963). A rapid procedure for catalase determination in blood and tissue samples with the Van Slyke manometric apparatus. Clinical Chemistry, 9: 763-775.

5. Rorth M \& J ensen PK (1967). Determination of catalase activity by means of the Clark oxygen electrode. Biochimica et Biophysica Acta, 139: 171-173.

6. Penasse L (1974). Les Enzymes: Cinétique et Mécanisme d'Action. Masson et Cie. Eds., Paris.
7. Takahara S, Hamilton HB, Neel J V, Kobara TY, Ogura Y \& Nishimura ET (1960). Hypocatalasemia: A new genetic carrier state. J ournal of Clinical Investigation, 39 : 610-619.

8. Chance B \& Maehly AC (1961). Biochemist's Handbook. E \& FN Spon Ltd., London, 383-384.

9. Dixon M \& Webb EC (1964). Enzymes. Academic Press, New York, 311-314.

10. Aebi H (1974). Catalase. In: Bergmeyer $\mathrm{HU}$ (Editor), Methods of Enzymatic Analysis. Vol. 2. Academic Press, New York, 673-684.

11. Setlow AB (1951). The inactivation of catalase by deuterons and heat. Archives of Biochemistry and Biophysics, 34: 396408.

12. Babenko GA \& Goinatski MN (1976). Determination of catalase activity in erythrocytes and serum by the iodometric method. Laboratornoe Delo, 3: 157-158.

13. Richardson $M$, Huddleson IF \& Bethea $R$
(1953). Study of catalase in erythrocytes and bacteria. I. Procedure for the determination of the catalase activity of erythrocytes. Archives of Biochemistry and Biophysics, 42: 114-123.

14. Kraitsev SI (1967). Method for the determination of the catalase activity in intact erythrocytes and hemolysed blood. Laboratornoe Delo, 9: 562-563.

15. Rigo A \& Rotilio C (1977). Simultaneous determination of superoxide dismutase and catalase in biological materials by polarography. Analytical Biochemistry, 21: 157-166.

16. Van Lente F \& Pepoy M (1990). Coupledenzyme determination of catalase activity in erythrocytes. Clinical Chemistry, 36: 339-343.

17. Goth L (1991). A simple method for determination of serum catalase activity and revision of reference range. Clinica Chimica Acta, 196: 143-151.

18. Yasmineh WG, Chung MY \& Caspers JI 
(1992). Determination of serum catalase activity on a centrifugal analyzer by an NADP/NADPH coupled enzyme reaction system. Clinical Biochemistry, 25: 21-27.

19. Sinha AK (1972). Colorimetric assay of catalase. Analytical Biochemistry, 47: 389394.

20. Ou P \& Wolff SP (1996). A discontinuous method for catalase determination at 'near physiological' concentrations of $\mathrm{H}_{2} \mathrm{O}_{2}$ and its application to the study of $\mathrm{H}_{2} \mathrm{O}_{2}$ fluxes within cells. J ournal of Biochemical and Biophysical Methods, 31: 59-67.

21. Maral J , Puget K \& Michelson AM (1977). Comparative study of superoxide dismutase, catalase and glutathione peroxidase levels in erythrocytes of different animals. Biochemical and Biophysical Research Communications, 77: 1525-1535.

22. Mueller S, Riedel HD \& Stremmel W
(1997). Determination of catalase activity at physiological hydrogen peroxide concentrations. Analytical Biochemistry, 245: 55-60.

23. Miller H (1958). The relationship between catalase and haemoglobin in human blood. Biochemistry J ournal, 68: 275-282.

24. Tudhope GR (1967). Red cell catalase in health and in disease, with reference to the enzyme activity in anaemia. Clinical Science, 33: 165-182.

25. Bonnichsen RK, Chance $B$ \& Theorell H (1947). Catalase activity. Acta Chemica Scandinavica, 1: 685-709.

26. Meldrum NU \& Roughton FJ W (1934). Carbonic anhydrase. Its preparation and properties. J ournal of Physiology, 80: 113141.

27. Beutler E \& Blaisdell RK (1958). Iron enzymes in iron deficiency. II. Catalase in human erythrocytes. J ournal of Clinical
Investigation, 37: 833-835.

28. Paul KG \& Engstedt L (1958). Normal and abnormal blood catalase activity in adults. Scandinavian J ournal of Clinical and Laboratory Investigation, 10: 26-33.

29. Engstedt L \& Paul KG (1960). Inter-individual variations in blood catalase activity. Scandinavian J ournal of Clinical and Laboratory Investigation, 12: 502-503.

30. Guemouri L, Artur $Y$, Herbeth B, J eandel C, Cuny G \& Siest G (1991). Biological variability of superoxide dismutase, glutathione peroxidase, and catalase in blood. Clinical Chemistry, 37: 1932-1937.

31. Bolzan AD, Bianchi MS \& Bianchi NO (1997). Superoxide dismutase, catalase and glutathione peroxidase activities in human blood: influence of sex, age and cigarette smoking. Clinical Biochemistry, 30: 449-454. 